Article

\title{
Restructuring China's Water Environment Management System: A Social Network Perspective
}

\author{
Lei Cheng ${ }^{1}$, Lei Shi ${ }^{2}$, Yuxi Xie ${ }^{1, *}$ and Weihua Zeng ${ }^{1, *}$ \\ 1 State Key Joint Laboratory of Environmental Simulation and Pollution Control, School of Environment, \\ Beijing Normal University, Beijing 100875, China; lierdetianya@163.com \\ 2 State Key Joint Laboratory of Environment Simulation and Pollution Control, School of Environment, \\ Tsinghua University, Beijing 100084, China; slone@tsinghua.edu.cn \\ * Correspondence: xieyx2017@mail.bnu.edu.cn (Y.X.); zengwh@bnu.edu.cn (W.Z.); \\ Tel.: +86-188-0111-3093 (Y.X.); +86-138-0117-5757 (W.Z.)
}

Received: 31 August 2020; Accepted: 29 September 2020; Published: 13 October 2020

\begin{abstract}
Despite restructuring in institutions related to environmental protection, the multi-sectorial decentralized water management system of China continued to be widely criticized. To identify the problems in China's water management system and the direction of future reform, this article implemented social network analysis. From multiple perspectives (covering efficiency analysis, condensation analysis, and network centrality analysis), we quantitatively analyzed the structural change of the super-ministry reform of water environment management in China. We found that the 2018 super ministry reform of the system made the aggregation and central enhancement of China's water management network, hence the power of water environmental management is more concentrated in the core department. However, the function overlap still exists after the reform. Some key issues of water resources management are absent from the responsibility of the core management department. Therefore, the cohesion and management effectiveness of the overall management network need to be further improved. Finally, we summarized several practical implications for future water management system reform, and the kernel is to achieve integrated management of water resource and water environment.
\end{abstract}

Keywords: social network analysis; water environment management; super-ministry reform

\section{Introduction}

To cope with serious water pollution, the State Council of China issued the Action Plan for Prevention and Control of Water Pollution (APPCWP) in April 2015 [1]. The plan consists of 10 primary water management responsibilities (including comprehensive control of pollutant emissions and promotion of economic restructuring, water protection and conversation, etc.), involving more than 30 management departments (including the Ministry of Environmental Protection (MEP), Ministry of Water Resources (MWR), Ministry of Land and Resources (MLR), etc.). APPCWP established common goals as a typical collective action under the government's mandatory orders and transparent responsibilities [2]. However, such large groups' higher organizational expenses also contribute to less cost-effective than other small groups [3,4]. Specifically, excessive management departments engaged in similar water management responsibilities would encounter many problems, such as overlapping functions and inefficient management. APPCWP involves over ten leading departments associated with each other regarding water pollution control. The Ministry of Water Resources and the Ministry of Environmental Protection have severe conflicts and overlaps in the protection of water resources and the prevention of water pollution.

In China, against the principle of unified supervision of water quality and quantity at the basin level emphasized by scholars $[5,6]$, two-lateral managing mechanisms in both water resource and 
water pollution often give rise to inefficiency and even failed management in facing complex situations. To reorganize the functions/responsibilities of government agencies, the Chinese government issued an institutional reform plan (called the super-ministry reform) in March 2018. After the reform, eight departments at the ministerial level were removed, while seven departments at the deputy ministerial level were abolished. However, it is unclear how much changes have been brought to the internal structure of China's water management system, and whether the reform improved management efficiency. Since the implementation time of the reform plan is not long, the research on the impact of the institutional change on China's water management efficiency is almost blank.

While many existing studies focused on analytical methods for water management (e.g., institutional change theory [7-9], adaptability management [10-12], conflict analysis [13], little investigated the role of institutional reform. Most researches about water governance are narrative review, decision-making recommendations, or qualitative analysis of management model $[3,14,15]$. They failed to offer a quantitative tool for supporting water management institution reform. Some studies suggested that it is more effective when studying the complex water management system and the other issues of natural resource management involving different stakeholders from the new perspective of social network analysis [16-19]. The social network analysis (SNA) developed as a favoured method to study social-structural patterns between actors in a social context, involving cooperation, knowledge transfer, consensus building and management efficiency, etc. [20]. Based on a series of graph theory tools and algebraic models, SNA provides a powerful model for depicting the invisible relationships. This method focuses more on the whole network's figure and the tangled links among the actors beyond the individual's attributes [21]. Characterizing individuals from the network perspective helps to unveil the underlying links between different individuals and their importance in the whole organization [22].

Based on the social network analysis method, the key research questions we proposed are how to quantify the water management system's effectiveness and whether the super-ministry reform in 2018 improved the management effectiveness. The paper's main contributions include two elements. First, we introduced the network analysis method to provide a new perspective on China's future water management system reform's quantitative research. Second, through exploring the structure change of the water management network in China caused by the super-ministry reform, the results of the network's stability and management effectiveness provide scientific policy implications for the top-level design of the future environmental protection super-ministry reform.

The paper is structured along the following line. Section 2 overviews the theoretical basis this paper builds on. Section 3 describes the government agency adjustment related to water environment management in the super-ministry reform of the State Council in 2018. Section 4 presents the specific method and research data. The network analysis results are discussed in Section 5 and brief conclusions and policy implications are drawn in Section 6.

\section{Theory}

\subsection{Collective Action and Social Network}

Collective action refers to action taken together by a group of people to improve their status and achieve common goals [23]. It is the main theoretical basis for exploring the logical rationality of integrated water resources management [24]. The social network, which can be defined as a specific system that people or institutions interact with each other [25], is a real collective action space.

APPCWP action plan is the highest standard and unprecedented water environment management action plan in China, involving almost all ministerial departments under the central government. This action plan, a typical organizational collective action, summarized in detail that each management responsibility corresponds to the specific leading and participating departments. This formal relationship between management responsibilities and management departments can be regarded as a 
management network or policy network with specific actors and links, where all actors share the same interests in solving a specific problem (i.e., water pollution control).

Policy networks should be seen as organized entities, and thus collectively acting units. The type of "multi-actor" joint action realized through policy networks should be regarded as a kind of collective action [26,27]. To date, policy networks are widely used to describe policy-making processes involving multiple government agencies, namely the function formulation and policy implementation. The policy network analysis mainly focuses on the redistribution of power among actors in a system. The specific operation of the power view of this relationship has been transformed into two types of research positions, mainly involving the position of actors in the network, as well as the relationship, between actors [28].

To summarize, networks can be a powerful image for describing the complex and new central water environment management morphology. Studies have revealed that the overall density of social connections in a group improves the prospect of collective action, and the concentration of network relations always has a positive impact on collective action [29]. We explored the APPCWP action plan's practical effectiveness by interpreting the water management system network implied in APPCWP. Through introducing the concept of collective action, we focused on whether the department allocation within the network effectively promotes the realization of collective goals. Naturally, investigating the interactions between individuals' motivation differences and network structure will contribute to a more comprehensive and sound analysis [30]. Without involving the difference of individual motivation as the traditional sociological collective action research is the limitation.

\subsection{New Institutional Economics}

One of the most important theoretical pillars of water environment management research is new institutional economics, which originated from Coase's article the nature of enterprises published in 1937 [31]. So far, new institutional economics has formed four basic theories: transaction cost theory, property rights theory, enterprise theory, and institutional change theory [32].

New institutional economics is an economic perspective regarding institutions as a kind of scarce resource. It holds that institutional efficiency is the optimal allocation issue that can be solved from a cost-benefit analysis. Based on its core theories of water rights, contract, and transaction cost, scholars have explained the challenges of integrated river basin management, public-private partnerships for water utilities, and the failure to privatize water utilities [24]. Different from the traditional new institutional economics research, we bypassed the traditional path of cost-efficiency analysis. From the perspective of network analysis, the spotlight was transferred from the evaluation of institutional efficiency to the stability of organizational network structure and the efficiency of the department's information transmission.

Nevertheless, the explanation of institutional cost in the new institutional economics still enlightened us. We try to shed light on the water management system's cost through the quantitative evaluation index of network analysis. Thus, by comparing whether the super-ministry reform can reduce the internal information communication cost or enhance management departments' cooperation efficiency, we explored China's water management system super-ministry reform's effectiveness.

\section{Water Environment Management System before and after the Restructuring of the State Council in 2018}

Before the restructuring of the State Council, China's water management system was a typical multi-center water management structure. Briefly, the Ministry of Water Resources (MWR) was responsible for the surface water conservancy and initial water supply to the city from the natural water body. The Ministry of Land and Resources (MLR) managed the underground water resource. The Ministry of Housing and Urban-Rural Development (MOHURD) oversaw urban water supply and wastewater treatment. The water quality of wastewater discharge or natural water was monitored by the Ministry of Environmental Protection (MEP). 
The State Council implemented the institutional reform plan in 2018, which simplified government structure and decentralized power. The super ministry reform integrated the responsibilities previously scattered in various ministries and commissions, especially in the environmental protection field (see Figure 1). To integrate the ecological environment protection responsibilities of various agencies, the Ministry of Ecological Environment (MEE) was established to exercise the functions of ecological environment and urban and rural pollution in a unified way.

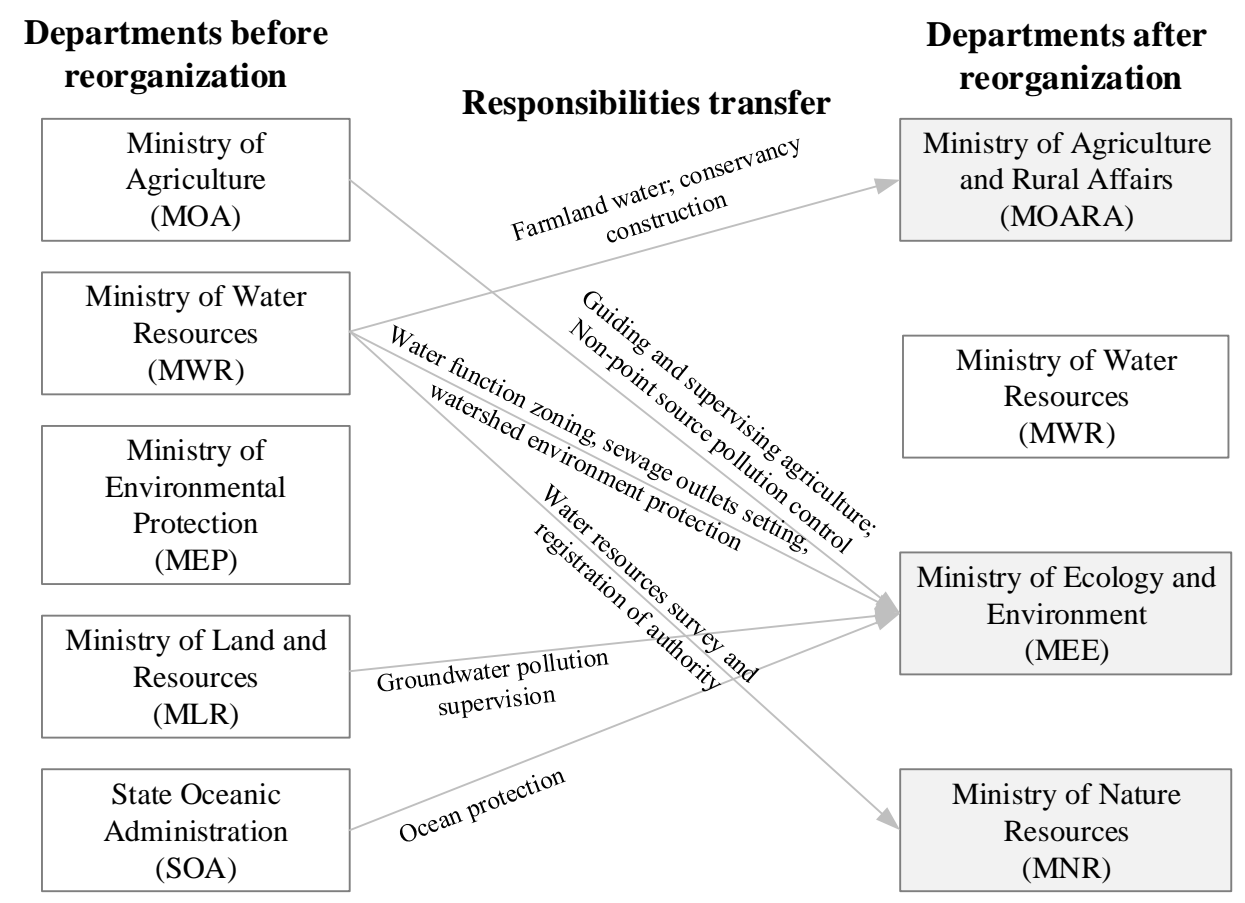

Figure 1. Institutional adjustment of water management in the government agency restructuring in 2018.

The Ministry of Agriculture (MOA) was renamed as the Ministry of Agriculture and Rural Affairs (MOARA). MOARA absorbed the duty of farmland water conservancy construction from the Ministry of Water Resources (MWR). The Ministry of Land and Resources (MLR) was renamed as the Ministry of Natural Resources (MNR), which incorporated the responsibility of water resources survey and authority registration from the Ministry of Water Resources (MWR). The Ministry of Environmental Protection(MEP) was renamed to the Ministry of Ecology and Environment (MEE), and acquired the responsibilities of guiding and supervising agricultural pollution control from the former Ministry of Agriculture (MOA); water function zoning, sewage outlets setting and watershed water environmental protection from the Ministry of Water Resources (MWR); groundwater pollution supervising from the former Ministry of Land and Resources (MLR); and marine protection from the former State Oceanic Administration (SOA) which was canceled in the government agencies restructuring. After this reorganization, MWP is mainly responsible for managing water resources utilization, river basins protection and water conservancy projects.

\section{Data and Methods}

\subsection{Data}

The data of water management network analysis in ministerial level is sourced from the 'Action Plan for Prevention and Control of Water Pollution' (APPCWP) issued by the State Council of China [33]. It is the top design for water management in China which itemized water management responsibilities from 2016 to 2030. 
From the document, we got a 'responsibility-agency' relational matrix of water management with 31 agencies and 76 management responsibilities, with assigning ' 2 ' or ' 1 ' to the 'relation value' between the agencies and responsibilities depending on whether the agency is primarily organizer or participant only.

After analyzing the water management network before the government agency restructuring, we readjusted the agencies at ministerial level and relative management responsibilities (responsibilities) of APPCWP in accordance to the government agency restructuring in March 2018. Adhere to the same principle of setting relationship data, subsequently we produced a new 'responsibility-agency' relational matrix of water management with 28 agencies and 76 management responsibilities. You can see the detailed matrixes in Supplementary Materials, Table S1.

\subsection{Social Network Analysis (SNA)}

Social network analysis is the method of studying a set of actors/responsibilities and their relationships. In a social network structure, the nodes represent actors/responsibilities and lines between the nodes represent the relationship within them. There contain many types of 'social network', which can be divided into 1-mode, 2-mode and others according to "modality" (numbers of types of actors/responsibilities). The 1-mode network refers to a type of actors/responsibilities and their internal relationships, while the 2-mode network concerns the relationship between a particular type of actors and its relative responsibilities or participating events [34]. In our research of water management system, "water management agency" can be regarded as "actor", and "water management responsibilities" can be regarded as "responsibilities". Hence both 2-mode relational network of 'agency-responsibility' and a 1-mode collaborative network of 'agency-agency', which can be covert into through the matrix transformation, can be constructed.

In the social network analysis, the common analysis methods mainly include quantitative analysis of overall network (degree, density, diameter, and centrality/centralization) and graphical/structural analysis (core/periphery structure, modularity), etc. [2]. The Ucinet, NetDraw, and Gephi which are visual and open-source software were selected for the analysis/visualization tool in the study. Specific analysis methods are as follows:

\subsubsection{Whole Network and Connectivity Efficiency Analysis}

The analysis indicators of the overall network mainly include average weighting degree, density, diameter, and average path. The average weighting degree is the degree calculation considering the weight of lines/edges between nodes, and the higher the average weighting degree, the tighter the connectivity between nodes. Density is the ratio of the number of lines (relationships) existing in the network to the maximum number of lines/edges (relationships) that may exist (the maximum value of density is 1) [35].

Generally speaking, the more relevancy between nodes in the network, the greater the network density, the stronger the cooperative relationship between management departments, the more conducive to maximizing the management effect [36]. Simultaneously, both practical experiences and simulation network theory have proved that too high network density may lead to the homogenization of information and knowledge. In other words, too many incredibly redundant relationships among actors, may reduce the effectiveness of the coordination network, reducing the ability of the network to adapt to changes in the external environment $[2,37]$.

The diameter is the maximum distance, and the average path is the average of the shortest distance between any two nodes in the network. They both characterize the information transmission efficiency of the network. The lower the value, the higher the efficiency [38].

\subsubsection{Network Centrality and Core-Periphery Structure Analysis}

The centrality measures the extent to which the node is in the center of the network, reflecting the importance of the node in the network. The network centralization measures the centralization trend 
of the whole network $[19,39]$. There are four types of centralities/centralizations based on different calculation modes: point centrality/centralization, closeness centrality/centralization, betweenness centrality/centralization and eigenvector centrality/centralization [38]. We mainly concerned about the eigenvector centrality/centralization, which emphasizes the significance of the node depends not only on the number of neighboring nodes but also on the importance of its neighboring nodes, and it can more accurately characterize the significance of nodes in the network. The core-periphery structure is a typical kind of social network structure, which can clearly depict who is the core node, in which nodes are inclined to co-occurring and closely connected with others in the network [40].

\subsubsection{Modularity Analysis}

Modularization analysis can classify nodes into differing cohesive subgroups based on the connection relationship of graphs [41]. There is structural equivalence to a certain extent between the nodes in the same module/group. The higher the average aggregation coefficient of the network, the lower the degree of modularity [42,43], that is, the fewer cohesive subgroups that can be clearly distinguished. Studies have shown that the existence of cohesive subgroups is not conducive to information communication and collaboration of the whole network [11]. However, when there is a proper bridge between subgroups, it is beneficial to the transfer of tacit knowledge. This bridge connecting different subgroups is conducive to the freer development of different types of management functions. In a word, a good management network system should strike a balance between network aggregation and network modularity [2], which can not only maximize the overall management efficiency of integrated management functions but also fully reflect some specific functions.

The visual analysis of modularization uses the "Fruchterman-Reingold" layout algorithm, which principle is to treat each node in the network as a point charge, and the connection between the two points (nodes) is treated as a spring [13]. The force of each point in the initial state can be calculated and the position information is updated until each point reaches equilibrium, to reduce the intersection of the edges in the layout and keep the length of the edges consistent. Then aggregation will be automatically complete, which can best facilitate direct observation of the closeness between nodes [44].

\section{Results and Discussion}

\subsection{2-Mode Network Analysis ('Responsibility-Agency' Network)}

\subsubsection{Overall Network Analysis}

The overall density of the 'responsibility-agency' network before the government restructuring is 0.062 , compared with 0.059 after the government restructuring. The average weighted degree of the 'responsibility-agency' network before the government restructuring is 8.243 , compared with 7.808 after the government restructuring. Most of the average weighted degrees are between 0 and 10 .

According to the results of the analysis of the overall network density index and the average weighting degree, the density of the network graph is very low. This result indicates that in the actual water management network of China, the operational connection degree between departments and responsibilities is very low, while the overall network structure is not close enough.

\subsubsection{Significant Analysis of Nodes}

For simple individual networks, the degree is often used to reflect the importance of nodes. In view of the complex structure of the water management network, the weight between nodes and nodes need to be considered. Combined with the analysis function of Gephi software, "PageRank" was used to quantitatively analyze the importance of the network nodes. "PageRank" is a tool for ranking webpage adopted by Google on the basis of eigenvector calculation. 
From the ranking of the top nodes, the essential departments in the Chinese water management network before the department restructuring were Ministry of Environmental Protection (MEP), Ministry of Water Resources (MWR), and other seven agencies (see Figure 2). These results suggest that the core management responsibilities improve related laws/regulations and taxation policies. They imply that many significant ministerial agencies were involved in water management in China. The laws and regulations, finance and taxation, $R \& D$ and departmental cooperation are the key tasks for APPCWP.

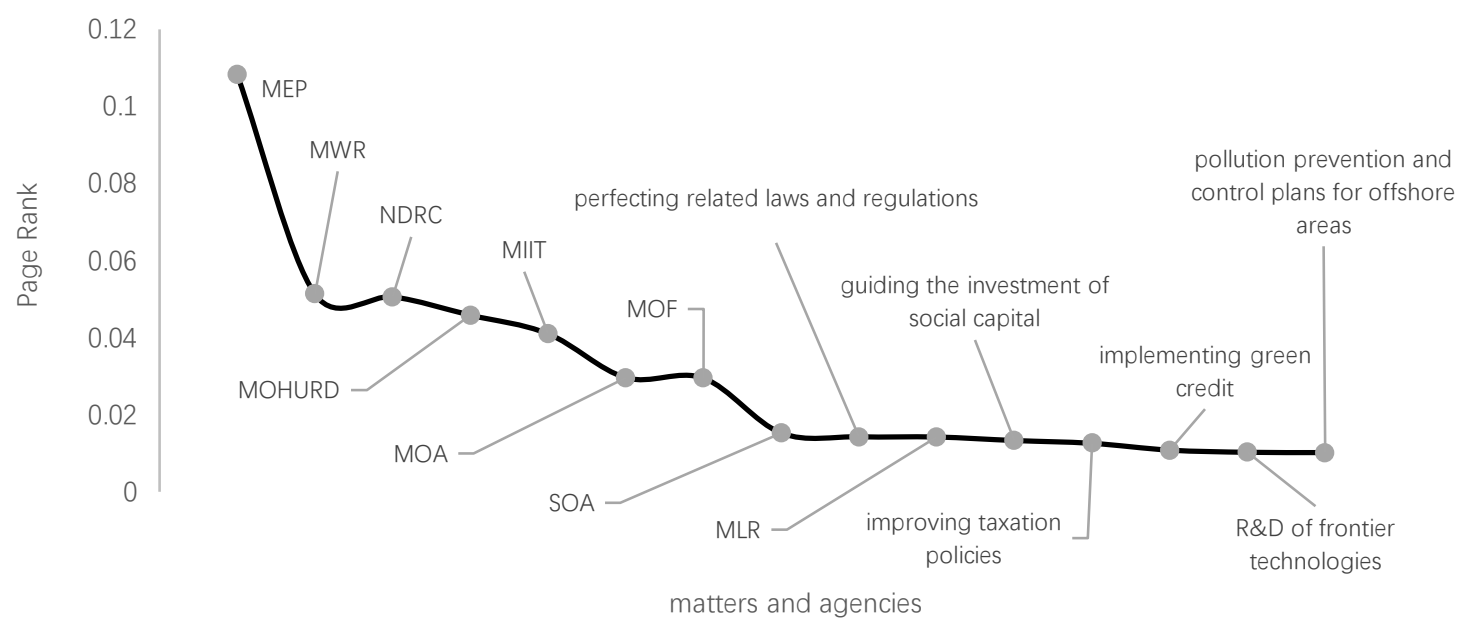

Figure 2. PageRank before the restructuring.

After the department restructuring (in 2018), apart from the core departments of public administration (e.g., National Development and Reform Commission (NDRC), the Ministry of Industry and Information Technology (MIIT) and the Ministry of Finance (MOF)), the newly established Ministry of Natural Resources (MNR) which was converted from the Ministry of Land and Resources (MLR) became more prominent (see Figure 3). By contrast, the former Ministry of Water Resources (MWR) and the Ministry of Agriculture (MOR) turned less important in the network.

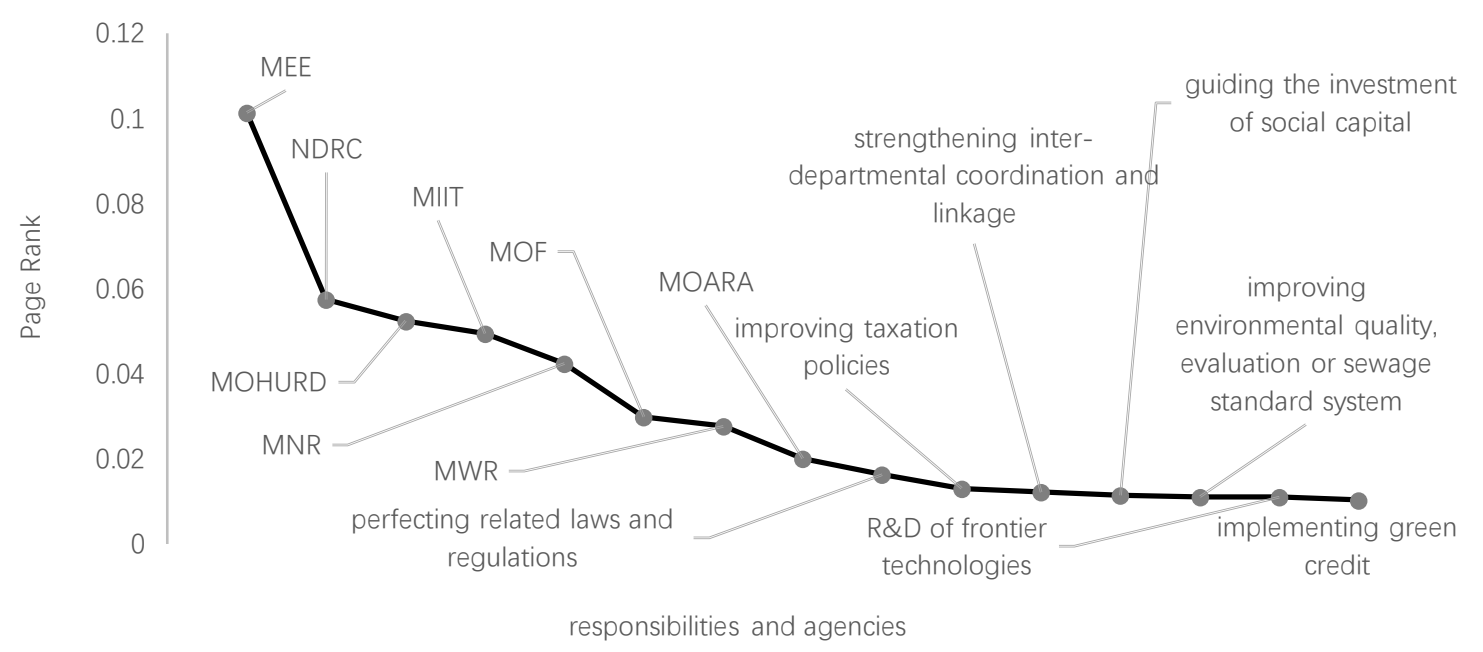

Figure 3. PageRank after the restructuring.

\subsubsection{Modularity Analysis}

The modularity and average clustering coefficient of the 2-mode network before the restructuring were 0.285 and 0 respectively, compared with 0.287 and 0 after the restructuring. This means no obvious small group clustering between water management agencies and management responsibilities in China, and both 2-mode networks ('responsibility-agency' network) are highly dispersed networks. 
The low degree of modularity indicates that there is no clear independent sub-module, which also leads to different analysis results in the process of modular analysis. After multiple rounds of analysis combined with our judgment (based on the knowledge about the actual water management situation), the modular analysis results with higher frequency are selected. They can be separated into seven and six groups, respectively; in different colors (see Figures 4 and 5).

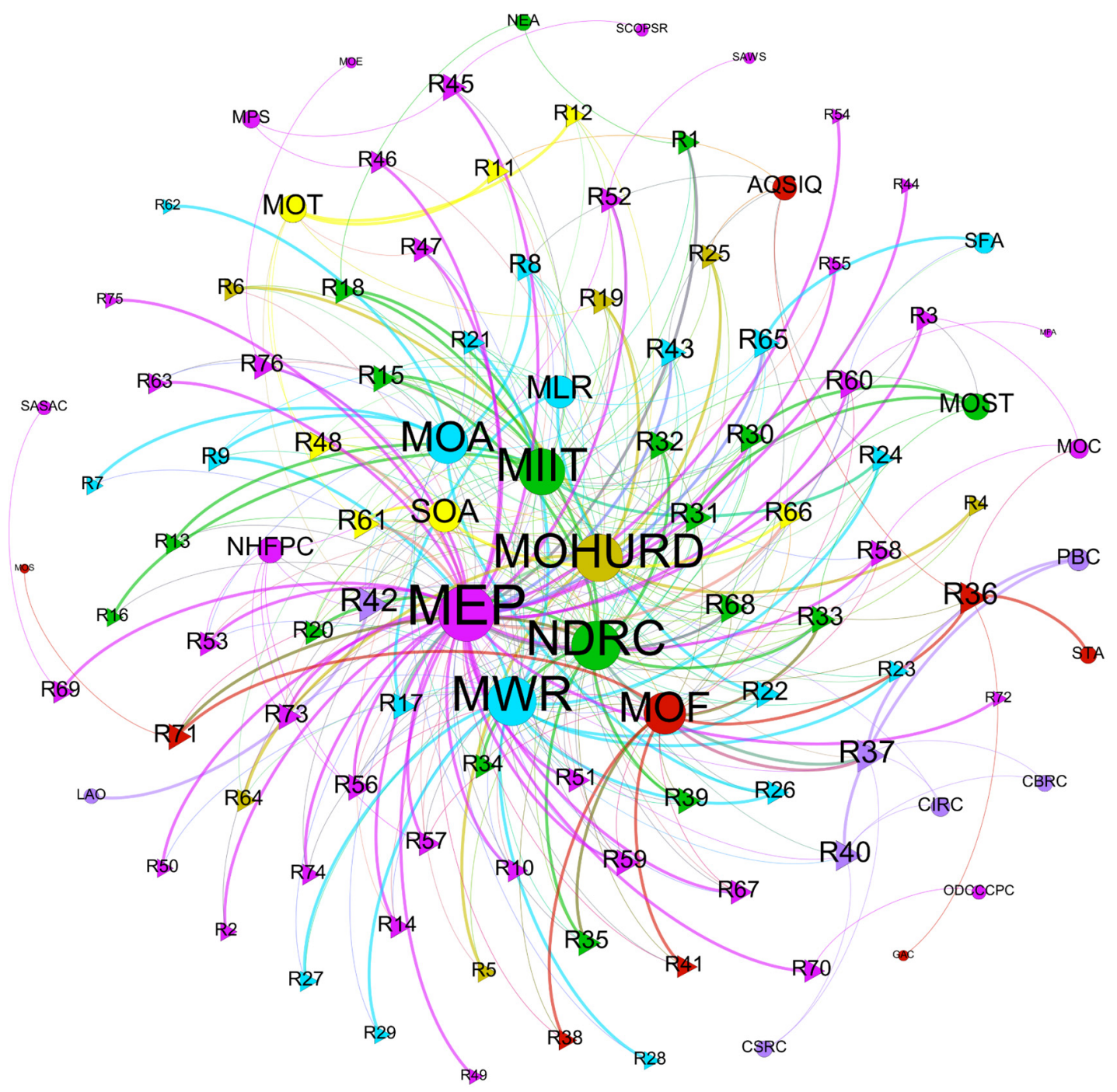

Figure 4. Whole network map of water management before the restructuring. Note: Circle nodes represent departments, and triangle nodes describe responsibilities. See Supplementary Materials, Table S1 for the original responsibility text of triangle node labels. The same as Figure 5. 


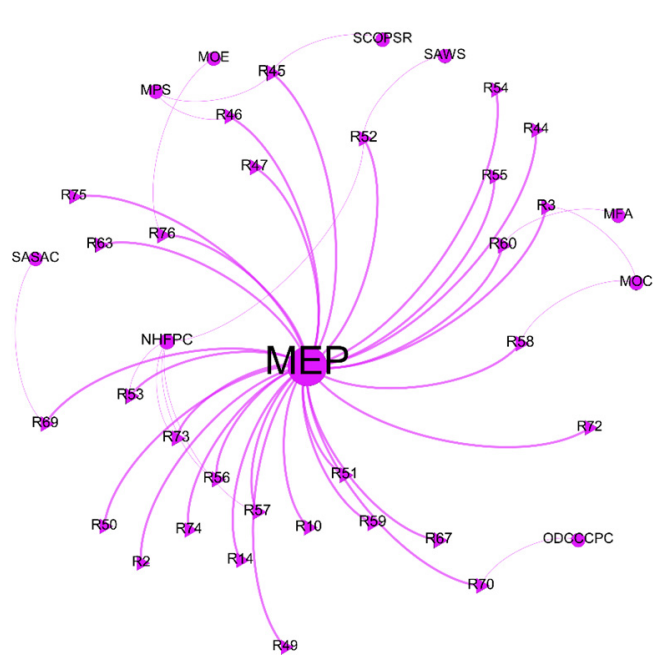

(a)

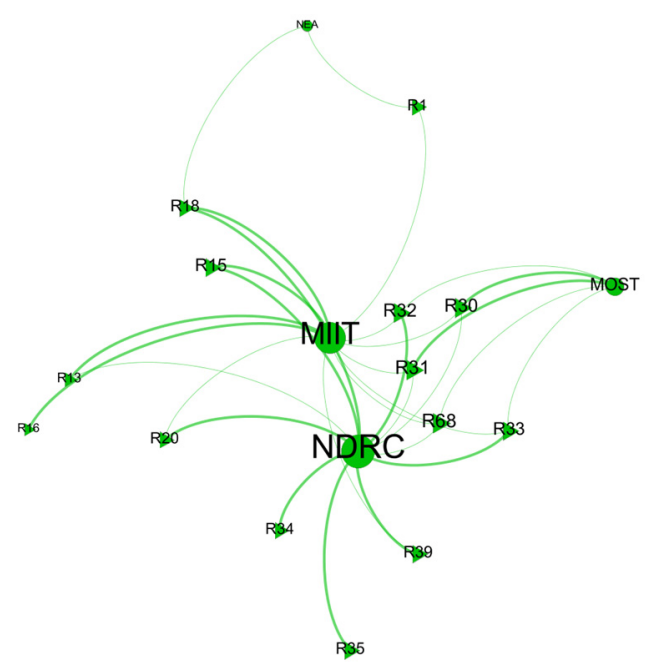

(c)

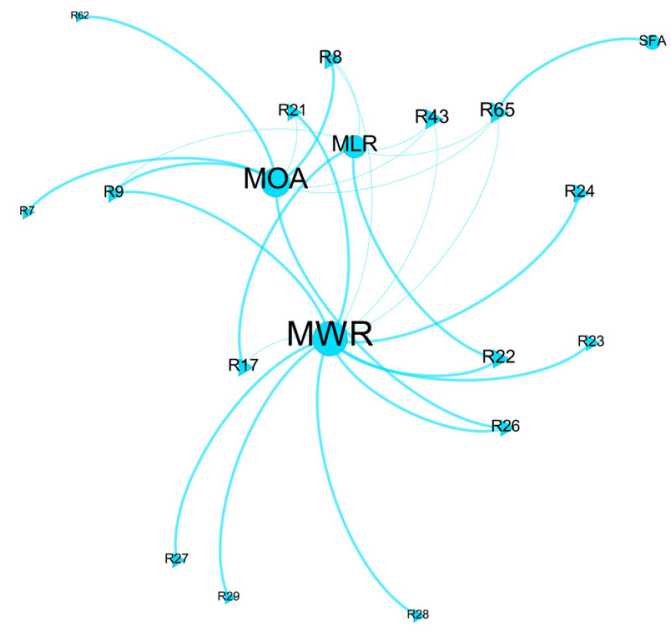

(b)

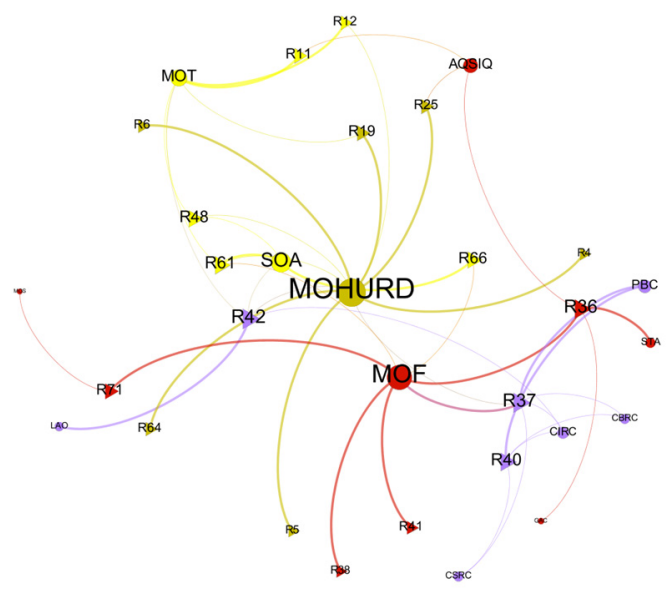

(d)

Figure 5. Sub-modules/groups of water management network before the restructuring; (a) M1; (b) M2; (c) M3; (d) M4-M7.

According to the theory of block model, a certain degree of structural equivalence between the sub-nodes exists in the same module, implying that some management departments are redundant in the same module. We can see from the first module (Figure 5a; in purple, with $36.45 \%$ of nodes), the core government agency is the Ministry of Environmental Protection (MEP), which is in charge of most of the responsibilities about water pollution and protection. The main government agencies in the second module (Figure $5 b$; in blue, contains $17.76 \%$ of nodes) are the Ministry of Agriculture (MOA), Ministry of Water Resources (MWR), and Ministry of Land and Resources (MLR). The sub-network is centered on the Ministry of Water Resources (MWR), which is mainly responsible for saving and protecting water resources. The Ministry of Water Resources (MWR) and Ministry of Land and Resources (MLR) play key roles in controlling groundwater overexploitation and protecting ecological space, respectively. At the same time, the Ministry of Water Resources (MWR) and Ministry of Agricultural (MOA) are related to the management of agricultural water-saving and non-point source pollution. In the third module (Figure $5 \mathrm{c}$; in green, with $16.82 \%$ of nodes), the main government agencies are the Ministry of Industry and Information Technology (MIIT), National Development and Reform Commission 
(NDRC) and Ministry of Science and Technology (MOST). The two major administrative departments of the NDRC and MITT cooperated closely in eliminating outdated industrial capacity, optimizing the spatial distribution, and promoting the exit of polluting enterprises. These promote the transformation of economic institutions. To strengthen science and technology support management, the MITT and NDRC cooperated closely in dissemination demonstration and appropriate technologies, R\&D frontier technologies, and vigorously developing environmental protection industries. Since the nodes of modules $4-7$ are relatively small (i.e., $8.41 \%, 7.48 \%, 6.54 \%$, and $6.54 \%$, respectively), they are shown in a sub-graph (Figure 5d). The functions of the Ministry of Transportation (MOT) and the State Oceanic Administration (SOA) overlap in several aspects (i.e., ship pollution treatment, enhancing the ability to prevent, and control of the port and terminal pollution). There are overlapping functions in the management of capital and green credit and guiding the investment of social capital among the People's Bank of China (PBC), China Securities Regulatory Commission (CSRC), China Banking Regulatory Commission (CBRC), and China Insurance Regulatory Commission (CIRC).

Modularization analysis of the 2-mode network structure after the reform is carried out. Six sub-modules are obtained (the nodes accounted for $42.31 \%, 15.38 \%, 12.5 \%, 11.54 \%, 9.62 \%$ and $8.65 \%$, respectively) (Figure 6). By comparing the results of the modularity analysis with the former, we can see that the number of nodes in the sub-module 1 (Figure 7a; in red) increased significantly, i.e., the management of water environment under the jurisdiction of the newly formed Ministry of Ecological Environment (MEE) has increased obviously, and the management power has increased. In the new sub-module 2 (Figure $7 \mathrm{~b}$; in yellow), the relationship between the Ministry of Industry and Information Technology (MIIT), National Development and Reform Commission (NDRC), and Ministry of Science and Technology (MOST) barely changed after the reform, which are still interwoven with the management responsibilities of science and technology supports. Modules 4-6 (Figure 7d) also show that the People's Bank of China (PBC), China Banking and Insurance Regulatory Commission (CBIRC), China Securities Regulatory Commission (CSRC) have cross functions in green credit and green financing. The sub-module 3 (Figure 7c; in green) indicates that the Ministry of Water Resources (MWR) and Ministry of Housing and Urban-Rural Development (MOHURD) have certain functions overlapping in promoting the utilization of reclaimed water. 


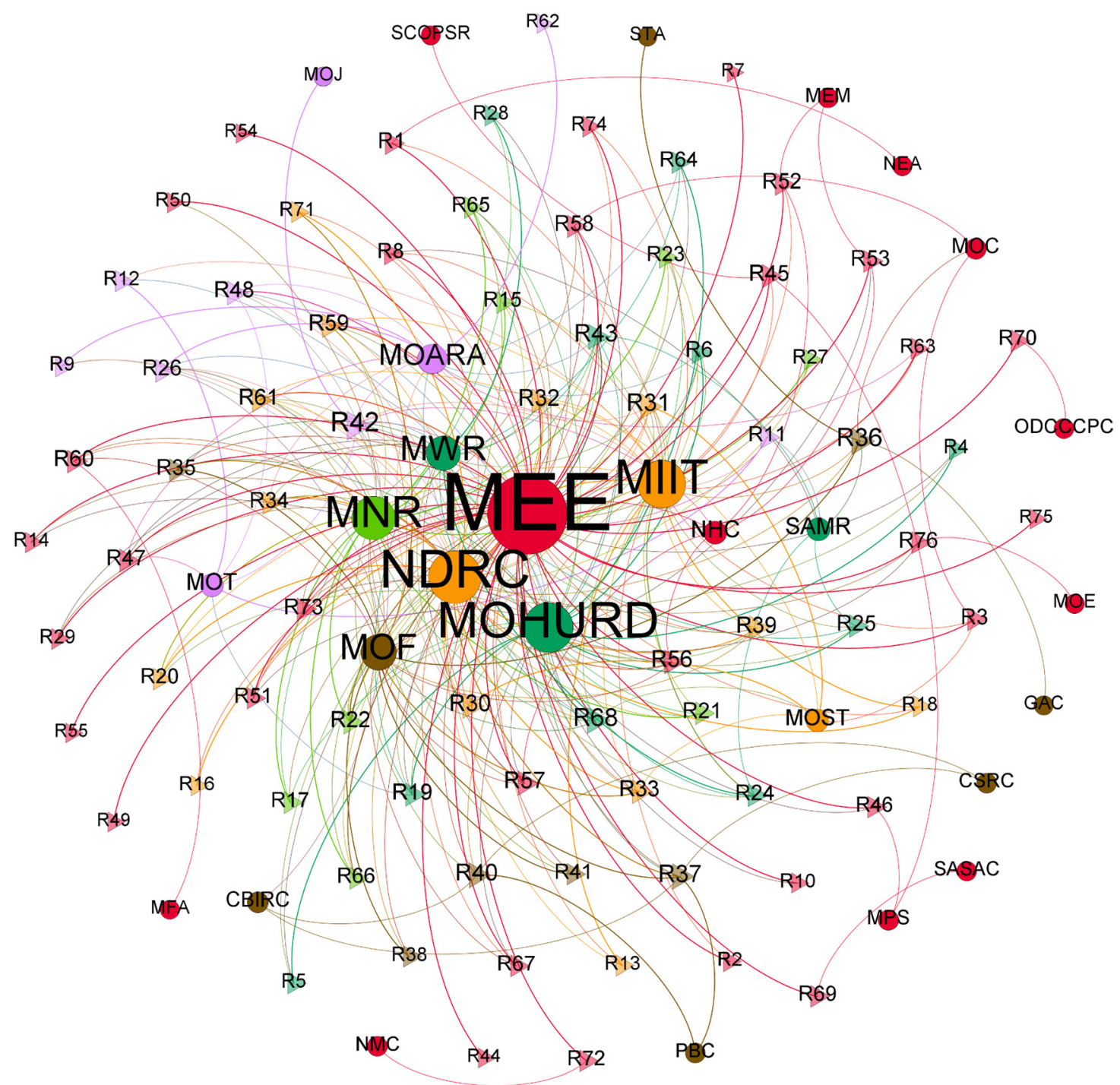

Figure 6. Whole network map of water management after the restructuring. Note: Circle nodes represent departments, and triangle nodes describe responsibilities. See Supplementary Materials, Table S1 for the original responsibility text of triangle node labels. The same as Figure 7. 


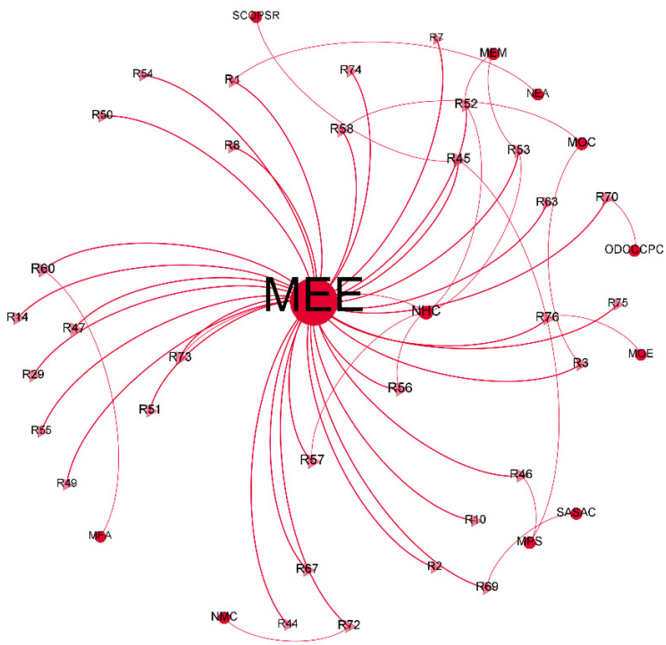

(a)

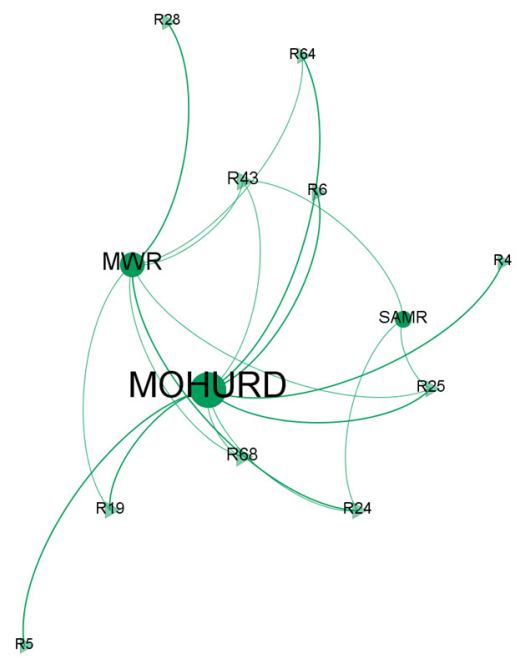

(c)

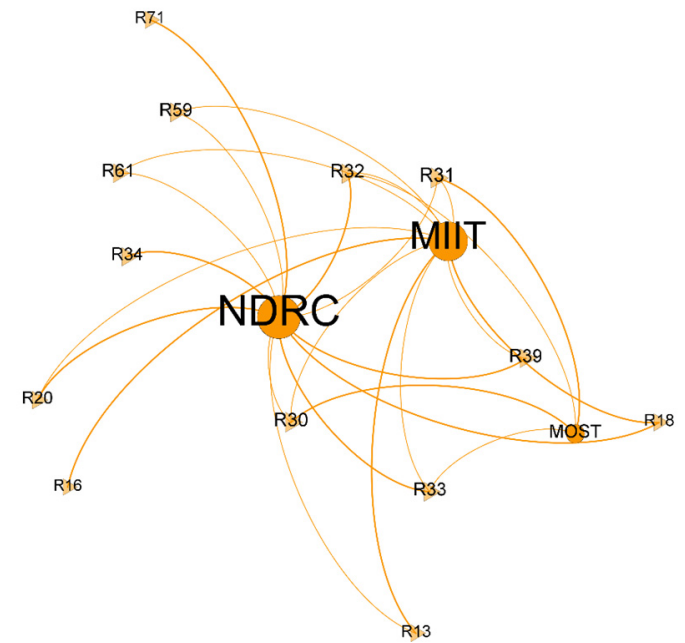

(b)

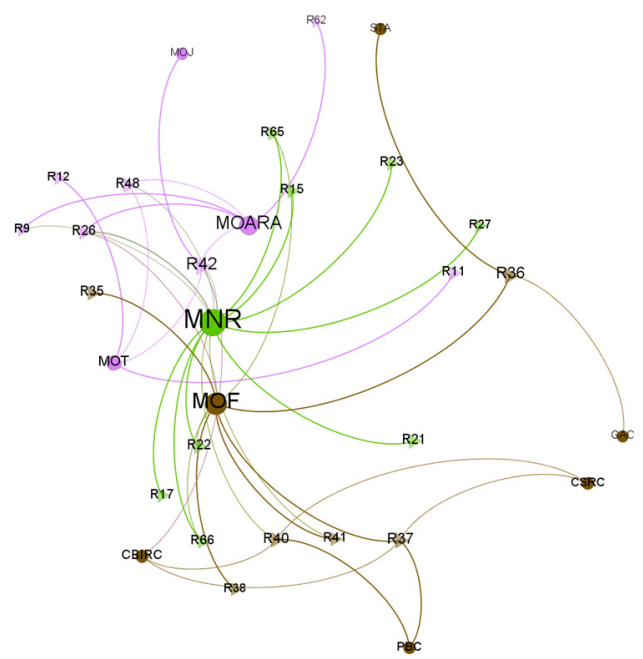

(d)

Figure 7. Sub-modules/groups of water management network after the restructuring; (a) M1; (b) M2; (c) M3; (d) M4-M6.

\subsection{1-Mode Network Analysis ('Agency-Agency' Network)}

In the analysis of the 1-mode network, the 2-mode network needs to be converted into a 1-mode network through the matrix transformation for exploring the relationship among the actors. The matrix can be transformed using the function of 'data-associate (2-mode to 1-mode)' in UCINET, and the conversion method can be selected using the 'minimums method' which is adaptable for multi-value data (the data not only include 0 or 1 ) [43].

\subsubsection{Core-Periphery Analysis}

By constructing the 'agency-agency' network in the core-periphery analysis, we explore the core agencies responsible for water management cooperation network in China. The network centralization index of the two networks (above) are $82.48 \%$ and $94.02 \%$ separately, which both close to 1 . This outcome means that there is probably one core in the cooperation network.

Figures 8 and 9 display the two water management agency networks with obvious core-periphery structure. Regarding the network before department restructuring, the Ministry 
of Environmental Protection (MEP), Ministry of Water Resources (MWR), Ministry of Housing and Urban-Rural Development (MHURD), Ministry of Industry and Information Technology (MIIT), National Development and Reform Commission (NDRC) are in the first core circle. The Ministry of Finance (MOF), Ministry of Agriculture (MOA), State Oceanic Administration (SOA), and Ministry of Land and Resources (MLR) are in the intermediate transition layer. The other twenty-two agencies are in the edge position of the water management system.

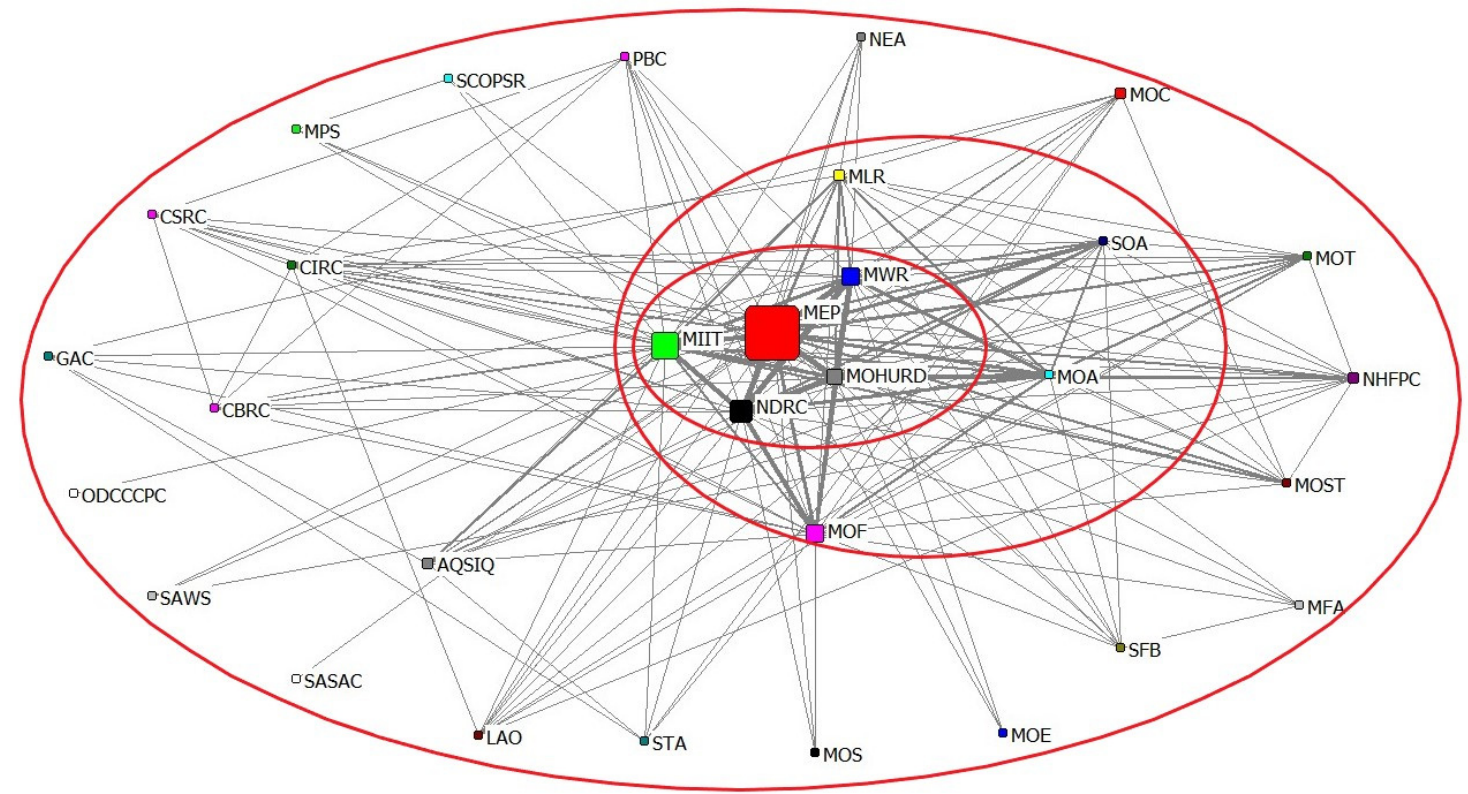

Figure 8. The core-periphery structure of water management structure before the restructuring.

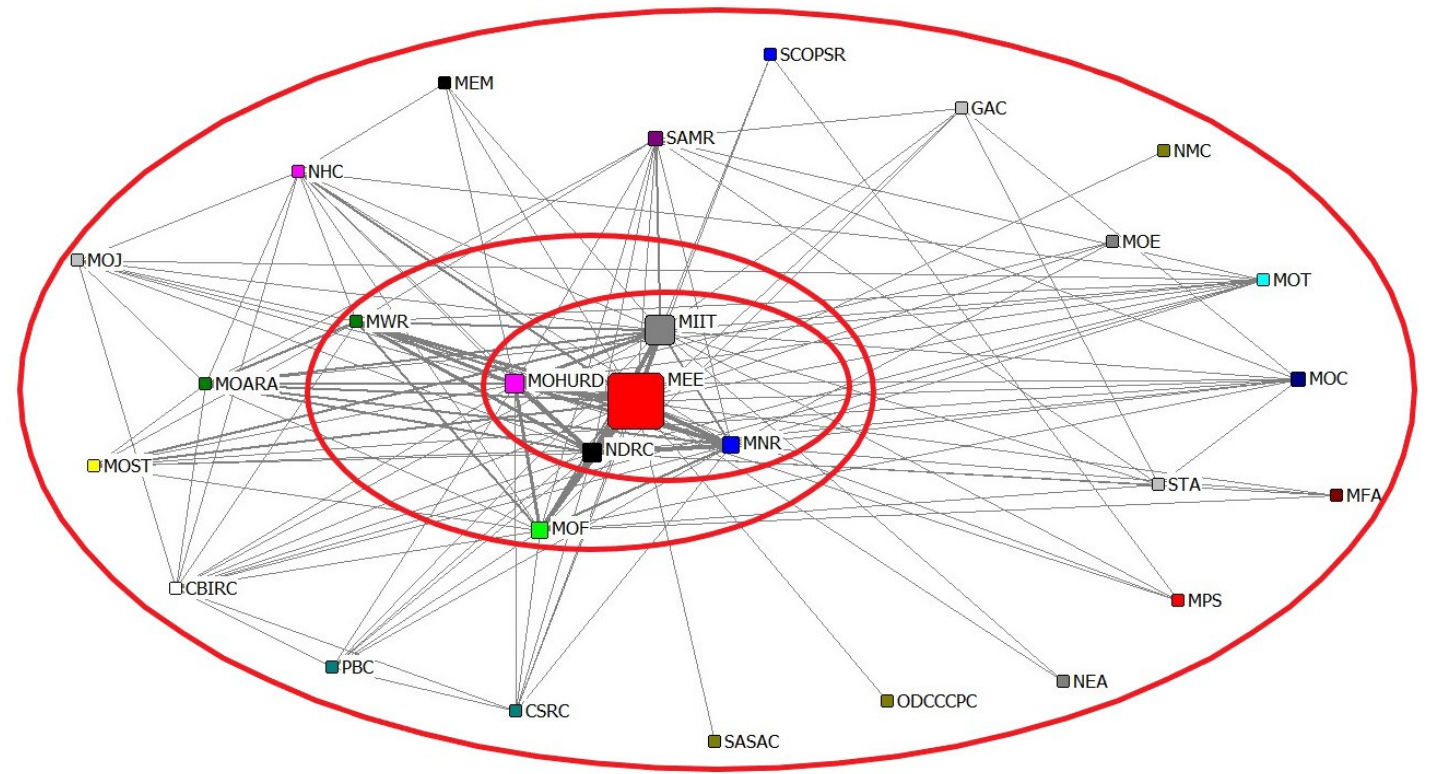

Figure 9. The core-periphery structure of water management structure after the restructuring.

For the network after department restructuring, the Ministry of Ecology and Environment (MEE), Ministry of Housing and Urban-Rural Development (MHURD), Ministry of Industry and Information Technology (MIIT), National Development and Reform Commission (NDRC), Ministry of Natural Resources (MNR) are in the first core circle. The Ministry of Finance (MOF) and the Ministry of Water Resources (MWR) are in the intermediate transition layer. The other 21 agencies are in the edge position of the water management system. 


\subsubsection{Connectivity Efficiency Analysis}

The average distance of the whole 1-mode network (i.e., the length of an optimal path between two nodes in a network) can be realized using distance matrix analysis function in UCINET. The results of before and after the department restructuring are 2.080 and 2.063, respectively; the simultaneously calculated network compactness indexes are 0.539 and 0.544 , respectively.

\subsection{Comparative Analysis of the Structure's Changes after the Government Restructuring}

By analyzing the 2-mode network and 1-mode network, we summarize the results of the three kinds of indexes of the two network structures before and after the reform. These indexes include the efficiency analysis index (diameter, average path length, and average distance), condensation index (average weighted degree and density), and network centrality index (network centralization index and core area node). The results of the comparative analysis are shown in Table 1.

Table 1. Comparison of the two management network structures in social network analysis.

\begin{tabular}{|c|c|c|c|c|}
\hline & Indicators & Property & Before the Reform & After the Reform \\
\hline \multirow{6}{*}{$\begin{array}{l}\text { 2-mode } \\
\text { (agency-responsibility) }\end{array}$} & Nodes & - & 107 & 104 \\
\hline & Edges & - & 349 & 318 \\
\hline & Diameter & Negative & 6 & 6 \\
\hline & Average path length & Negative & 2.50 & 2.48 \\
\hline & Average weighted degree & - & 8.243 & 7.808 \\
\hline & Density & - & 0.062 & 0.059 \\
\hline \multirow{4}{*}{$\begin{array}{c}\text { 1-mode } \\
\text { (agency-agency) }\end{array}$} & $\begin{array}{c}\text { Distance-based cohesion } \\
\text { ("Compactness") }\end{array}$ & Positive & 0.539 & 0.544 \\
\hline & Average distance & Negative & 2.080 & 2.063 \\
\hline & $\begin{array}{l}\text { Network centralization index } \\
\qquad(\%)\end{array}$ & Positive & 82.48 & 94.02 \\
\hline & $\begin{array}{c}\text { Significant nodes } \\
\text { (core/periphery structure) }\end{array}$ & - & $\begin{array}{c}\text { MEP } \\
\text { MWR } \\
\text { NDRC } \\
\text { MOHURD } \\
\text { MIIT }\end{array}$ & $\begin{array}{c}\text { MEE } \\
\text { NDRC } \\
\text { MOHURD } \\
\text { MIIT } \\
\text { MNR }\end{array}$ \\
\hline
\end{tabular}

Firstly, the results of the efficiency analysis index show that the network diameter, average path length, and average distance are smaller after the reform; that is, a higher information transmission efficiency of the restructured network. The results of the condensation index (average weighted degree and density) reflect a decrease in the condensation of the 2-mode network. However, the 1-mode network cohesion between the management departments has been enhanced, further combined with the results of the central analysis. Therefore, the network centrality of the agencies after the reform is enhanced.

\section{Conclusions and Policy Implications}

The social network analysis method provides a new perspective for understanding the management system reform through a combination of qualitative and quantitative research methods. It allows for analyzing the relationship and structure between management responsibilities and management agencies; and the relationship between agencies. In this way, the structural features of the whole and partial network can be investigated.

Through the quantitative analysis of China's water management system network before and after the reform, we found that China's water management involved many major management departments before the department restructuring. Specifically, water environmental management, water resources management, and water protection were in different ministries departments, resulting in decentralized power and crossed function. We confirmed that the 2018 super ministry reform of the system led to 
these outcomes: more centralized water management rights; closer links between the core management departments, thus the power of water environmental management is more concentrated in the core department of power; and improvement in the overall stability and effectiveness for coordination of the network.

However, the function overlap still exists after the reform. The key issues of water resources management are not the responsibility of the core management department, but are managed by the Ministry of Natural Resources (MNR) and Ministry of Water Resources (MWR). In this sense, the cohesion and coordination effectiveness of the overall management network need to be further rectified.

Based on the above analysis, we summarize some policy implications. The future water management reform should clarify the leading and auxiliary management agency and relative responsibilities; further, integrate water management's responsibilities from non-core departments into core departments. The explicit implementation path could be: Firstly, establish a unique overlapping business coordination mechanism to promote the effective internal communication among the leading departments of the Ministry of Ecological Environment, the Ministry of Water Resources, and the Ministry of Natural Resources; Secondly, gradually concentrate the functions related to the water environment and water resources scattered in other departments to the Ministry of Ecological Environment to maximize the reduction of water management functional overlap; Finally strive to achieve integrated management of resources, environment, and ecology. These improvements should support building a scientific, efficient, and rational water environment management system in China.

Supplementary Materials: The following are available online at http://www.mdpi.com/2071-1050/12/20/8422/s1, Table S1: Inputed matrix data before and after the reform.

Author Contributions: Conceptualization, L.C. and W.Z.; methodology, L.C.; software, L.C.; validation, L.C. and Y.X.; formal analysis, L.C. and Y.X.; investigation, L.C.; data curation, Y.X.; writing-original draft preparation, L.C. and Y.X.; writing - review and editing, L.S.; visualization, L.C. and Y.X.; supervision, L.S. and W.Z.; funding acquisition, W.Z. All authors have read and agreed to the published version of the manuscript.

Funding: This work was supported by the Major Science and Technology Program on Water Pollution Control and Treatment (No.2018ZX07111003).

Conflicts of Interest: The authors declare no conflict of interest.

\section{References}

1. Risk, C.W. New 'Water Ten Plan' to Safeguard China's Waters. Available online: http://www.chinawaterrisk. org/notices/new-water-ten-plan-to-safeguard-chinas-waters/ (accessed on 6 June 2019).

2. Bodin, Ö.; Crona, B.I. The role of social networks in natural resource governance: What relational patterns make a difference? Glob. Environ. Change 2009, 19, 366-374. [CrossRef]

3. Ananda, J.; Proctor, W. Collaborative approaches to water management and planning: An institutional perspective. Ecol. Econom. 2013, 86, 97-106. [CrossRef]

4. Scholz, J.T.; Berardo, R.; Kile, B. Do networks solve collective action problems? Credibility, search, and collaboration. J. Politics 2008, 70, 393-406. [CrossRef]

5. Radif, A.A. Integrated water resources management (IWRM): An approach to face the challenges of the next century and to avert future crises. Desalination 1999, 124, 145-153. [CrossRef]

6. Zeng, W.; Zhang, Q. Primary research on innovation of water environmental management system in China. Tech. Equip. Enviroment. Poll. Cont. 2002, 12, 92-95. (In Chinese)

7. Bellamy, J.; Head, B.W.; Ross, H. Crises and institutional change: Emergence of cross-border water governance in Lake Eyre Basin, Australia. Soc. Nat. Resour. 2017, 30, 404-420. [CrossRef]

8. Beunen, R.; Patterson, J. Analysing institutional change in environmental governance: Exploring the concept of 'institutional work'. J. Environ. Plan. Manag. 2019, 62, 12-29. [CrossRef]

9. Thiel, A. Developing an analytical framework for reconstructing the scalar reorganization of water governance as institutional change: The case of Southern Spain. Ecol. Econ. 2014, 107, 378-391. [CrossRef]

10. Azhoni, A.; Holman, I.; Jude, S. Adapting water management to climate change: Institutional involvement, inter-institutional networks and barriers in India. Glob. Environ. Change 2017, 44, 144-157. [CrossRef] 
11. Crow-Miller, B.; Chang, H.; Stoker, P.; Wentz, E.A. Facilitating collaborative urban water management through university-utility cooperation. Sustain. Cities Soc. 2016, 27, 475-483. [CrossRef]

12. Peat, M.; Moon, K.; Dyer, F.; Johnson, W.; Nichols, S.J. Creating institutional flexibility for adaptive water management: Insights from two management agencies. J. Environ. Manag. 2017, 202, 188-197. [CrossRef] [PubMed]

13. Zeitoun, M.; Mirumachi, N.; Warner, J.; Kirkegaard, M.; Cascão, A. Analysis for water conflict transformation. Water Int. 2020, 45, 365-384. [CrossRef]

14. Araral, E.; Wang, Y. Does water governance matter to water sector performance? Evidence from ten provinces in China. Water Policy 2015, 17, 268-282. [CrossRef]

15. Nastar, M.; Ramasar, V. Transition in South African water governance: Insights from a perspective on power. Environ. Innov. Soc. Transit. 2012, 4, 7-24. [CrossRef]

16. Gajdoš, P.; Uher, V.; Dohnálek, P. A parallel Fruchterman-Reingold algorithm optimized for fast visualization of large graphs and swarms of data. Swarm Evol. Comput. 2016, 26, 56-63. [CrossRef]

17. Lienert, J.; Schnetzer, F.; Ingold, K. Stakeholder analysis combined with social network analysis provides fine-grained insights into water infrastructure planning processes. J. Environ. Manag. 2013, 125, 134-148. [CrossRef]

18. Ruzol, C.; Banzon-Cabanilla, D.; Ancog, R.; Peralta, E. Understanding water pollution management: Evidence and insights from incorporating cultural theory in social network analysis. Glob. Environ. Change 2017, 45, 183-193. [CrossRef]

19. Stein, C.; Ernstson, H.; Barron, J. A social network approach to analyzing water governance: The case of the Mkindo catchment, Tanzania. Phys. Chem. Earth Parts A B C 2011, 36, 1085-1092. [CrossRef]

20. Scott, J. Social network analysis. Sociology 1988, 22, 109-127. [CrossRef]

21. Newman, M.E. Modularity and community structure in networks. Proc. Natl. Acad. Sci. USA 2006, 103, 8577-8582. [CrossRef] [PubMed]

22. Prell, C.; Hubacek, K.; Reed, M. Stakeholder analysis and social network analysis in natural resource management. Soc. Nat. Res. 2009, 22, 501-518. [CrossRef]

23. Dowding, K. Collective Action Problem. Available online: https://www.britannica.com/topic/collectiveaction-problem-1917157 (accessed on 18 December 2019).

24. Araral, E.; Wang, Y. Water governance 2.0: A review and second generation research agenda. Water Res. Manag. 2013, 27, 3945-3957. [CrossRef]

25. Alhajj, R.; Rokne, J. Encyclopedia of Social Network Analysis and Mining; Springer Publishing Company, Incorporated: New York, NY, USA, 2014.

26. Carlsson, L. Policy networks as collective action. Policy Stud. J. 2000, 28, 502-520. [CrossRef]

27. Kenis, P.; Schneider, V. Policy networks and policy analysis: Scrutinizing a new analytical toolbox. In Policy Networks: Empirical Evidence and Theoretical Considerations; Campus Verlag: Frankfurt, Germany, 1991; pp. 25-29.

28. Lotan, G.; Graeff, E.; Ananny, M.; Gaffney, D.; Pearce, I. The Arab Spring|The revolutions were tweeted: Information flows during the 2011 Tunisian and Egyptian revolutions. Int. J. Commun. 2011, 5, 31.

29. Marwell, G.; Oliver, P.E.; Prahl, R. Social networks and collective action: A theory of the critical mass. III. Am. J. Soc. 1988, 94, 502-534. [CrossRef]

30. Siegel, D.A. Social networks and collective action. Am. J. Pol. Sci. 2009, 53, 122-138. [CrossRef]

31. Coase, R.H. The nature of the firm. Economica 1937, 4, 386-405. [CrossRef]

32. Ménard, C.; Shirley, M.M. Handbook of New Institutional Economics; Springer: Berlin/Heidelberg, Germany, 2005; Volume 9.

33. The State Council, The People's Republic of China. Circular of the State Council on Issuing Action Plan for Water Pollution Prevention and Control; The State Council, The People's Republic of China: Beijing, China, 2015. (In Chinese)

34. Borgatti, S.P.; Mehra, A.; Brass, D.J.; Labianca, G. Network analysis in the social sciences. Science 2009, 323, 892-895. [CrossRef]

35. Borgatti, S.P. 2-Mode concepts in social network analysis. Encyclopedia Complex Syst. Sci. 2009, 6, 8279-8291.

36. Pretty, J.; Ward, H. Social capital and the environment. World Dev. 2001, 29, 209-227. [CrossRef]

37. Little, L.R.; Mcdonald, A.D. Simulations of agents in social networks harvesting a resource. Ecol. Modelling 2007, 204, 379-386. [CrossRef] 
38. Borgatti, S.P.; Everett, M.G.; Johnson, J.C. Analyzing Social Networks; Sage: Thousand Oaks, CA, USA, 2018; Volume 16.

39. Scott, J. Social network analysis: Developments, advances, and prospects. Soc. Net. Anal. Min. 2011, 1, 21-26. [CrossRef]

40. Jones, C.; Hesterly, W.S.; Borgatti, S.P. A general theory of network governance: Exchange conditions and social mechanisms. Acad. Manag. Rev. 1997, 22, 911-945. [CrossRef]

41. Fliervoet, J.; Geerling, G.; Mostert, E.; Smits, A. Analyzing collaborative governance through social network analysis: A case study of river management along the Waal River in The Netherlands. Environ.Manag. 2016, 57, 355-367. [CrossRef]

42. Hu, X.; Lovelock, B.; Ying, T.; Mager, S. Stakeholder collaboration on policymaking for sustainable water management in Singapore's hotel sector: A network analysis. Sustainability 2019, 11, 2360. [CrossRef]

43. Kurian, M.; Portney, K.E.; Rappold, G.; Hannibal, B.; Gebrechorkos, S.H. Governance of water-energy-food Nexus: A social network analysis approach to understanding agency behaviour. In Managing Water, Soil and Waste Resources to Achieve Sustainable Development Goals; Springer: Berlin, Germany, 2018; pp. 125-147.

44. Ostrom, E. Collective action and the evolution of social norms. J. Econ. Perspect. 2014, 6, 235-252. [CrossRef]

(C) 2020 by the authors. Licensee MDPI, Basel, Switzerland. This article is an open access article distributed under the terms and conditions of the Creative Commons Attribution (CC BY) license (http://creativecommons.org/licenses/by/4.0/). 